\title{
Investigating the characteristics of patents and the businesses which hold them
}

Andrew Thomas

Office for National Statistics

\section{Summary}

This article describes how patent data from the UK Intellectual Property Office has been matched at the firm-level with the business surveys administered by the Office for National Statistics. The resulting dataset should provide a useful resource for those undertaking research on innovation in the UK. Some initial analysis of the matched dataset has been presented here. Results show that businesses hold more patents than individuals; large businesses hold more patents than small businesses on average; and businesses patent inventions which would be intuitively associated with their industry.

\section{Introduction}

Intellectual property, along with other knowledge assets, has become increasingly important to economies across the world. Recent estimates suggest that firms' investment in intangible assets has overtaken that of tangible capital (OECD 2009). Consequently, policy interest in this area has been growing, and the desire for policy evidence has been driving research in the innovation field. Patent statistics have provided one source of data for this research.

This article describes how patent and business datasets have been matched at the firm-level and provides some initial results from analysis of these data. The concept of combining patent and business databases is not novel ${ }^{1}$ but the analysis in this article is based on patent data from the UK Intellectual Property Office (IPO) which have not previously been made available for research. The matched data also provide a first step towards being able to associate innovative activity to a particular enterprise and location. Previous research has been able to identify whether a particular firm may exploit the intellectual property associated with a patent, for example as part of an international group that owns the patent, but until now it has been difficult to determine if a particular business at a particular location actually applied for the patent. The reason for this is the use of 'name only' matching of patent and business data sources. Matching by name and address can reduce the raw counts of matched observations, but has the added refinement of ensuring that 
the branch of the corporation which applied for the patent is the business with which a match is found.

The name and address matching in this instance is not directly with a business database. Rather, the names and addresses from the patent data are matched to the Inter-Departmental Business Register (IDBR) held by the Office for National Statistics (ONS). The IDBR is a live updating register of businesses in the UK, and is used as a sampling frame for the business surveys undertaken by ONS. The Enterprise Reference Numbers from the IDBR were attached to the patent data when a match was found. These reference numbers are common to all of the ONS's business surveys and the research possibilities arising from this are wide ranging as the patent data could be matched to any of these surveys.

The IPO is particularly interested in obtaining information about the characteristics of businesses that hold patents. Using the newly matched database, this article presents some initial findings on:

- the distributions of patents by age and size of their respective patentees

- the age and size distributions of the patentees themselves

- trends in the total stock of patents over time

- differences in patenting by businesses and individuals, and

- the relationship between the industry in which a business operates and the types of inventions being patented (based on International Patent Classification (IPC) codes)

The results suggest that the stock of patents is increasing over time, along with the number of patentees. In general, larger more established businesses hold more patents than smaller younger businesses. An investigation in to the types of inventions being patented reveals that businesses tend to patent inventions which have some logical link to the industry in which they operate. Finally, businesses hold significantly more patents than individuals.

The rest of this article proceeds as follows. The next section describes the sources for patent and business data. The third section explains the matching process. The fourth section presents some results from analysing the matched data set, and finally some brief conclusions are offered.

\section{Data sources}

\section{Patent data}

Two sources of patent data have been used in this work. The UK IPO provided a data extract from their Optics system, and use of the PATSTAT database containing information on patents applied for at the European Patent Office (EPO) was granted. Together these two data sources contain information on all patents applied for at the IPO or the EPO. However, as the aim of the matching exercise is to link UK business information with the patents held by those businesses, only the patents which have been applied for from a UK address are considered. 


\section{Optics}

Optics is the live register used by the IPO for the management of patent information. This database is updated every time a patent is applied for, published, amended or granted. To use this data for research purposes an extract has been taken which includes published patents that were applied for after 1990 and also all patents which have been granted since 1990. Naturally there is considerable crossover between the two, but there are a number of patents that were applied for before 1990 but granted afterwards. The data from 1986 to 2008 contains at least 2,000 observations per year. There are limited numbers of observations from 1977 to 1985 and in 2009. There is a time lag between when a patent is applied for and when it is published. The small number of observations prior to 1986 represent a longer than usual time lag, whilst the small number of observations in 2009 represent patents which have been published much more quickly than usual.

Optics is a live updating system so any new information is recorded in the same place as the existing information. For example, if a patent is renewed, the renewal date and annuity date are simply changed for that particular patent. As a result, all of the information extracted from Optics is attached to each observation. Aside from matching names and addresses to IDBR reference numbers, there was very little manipulation of the Optics data required to make it suitable for research.

\section{PATSTAT}

PATSTAT is a database of international patent statistics administered by the EPO and has been specifically designed for research purposes. PATSTAT data contains information on patents that were applied for between 1986 and 2009. Between 1986 and 2007 there are at least 3,000 observations per year, whilst there are fewer observations for 2008 to 2009 . As with Optics, this drop in the number of observations in recent years comes as a result of the time lag between the application and publication of a patent.

Despite being designed for research purposes, a certain amount of data manipulation was required before PATSTAT data could be analysed. As PATSTAT is not a live updating register, new information is not simply captured in the existing observation for a patent. For instance, a patent application and publication come in separate observations resulting in multiple observations per patent. It is known that the patents in the PATSTAT data have been published, and the information in the separate observations is otherwise identical. Therefore it was decided to simply keep the application observation for each patent.

The IPC codes for PATSTAT come in a separate file. As this information has one observation per IPC code rather than one observation per patent there are multiple observations per patent because each patent can have multiple IPC codes. To deal with this issue, the intention was to obtain the primary IPC code at the three character level of aggregation (the first three characters of the primary IPC code). To determine the primary IPC when there are multiple codes per patent, a marker was used indicating ' $F$ ' or ' $L$ '. This marker is present in less than half of the IPC dataset. The author was initially informed that this code indicated the first and last IPC for the patent, and 
attached the code marked ' $F$ ' to the patent data. When this marker was unavailable, a new variable containing only the first three characters of the IPC codes was created.

In the cases where the 3 character IPC code was the same for all observations relating to a particular patent, this IPC code was attached to the patent data. For the remaining cases where there was uncertainty regarding the primary IPC code, the IPC variable was left as a missing value in the patent data. Subsequent to this process and the production of the results presented here, the author was informed that the ' $F$ ' marker does not carry the meaning which was initially given. The consequence of which is that the results using IPC codes in this article may be spurious to a certain extent. As these results are presented at the 3 character level, and only a proportion of the PATSTAT data which has been affected, it is believed these consequences to be relatively minor but any future research on this database should bear in mind that the IPC codes for the PATSTAT information need further cleaning.

The patent information which is present in both the Optics and PATSTAT data and is used in this report is:

- Priority Year - the initial year that the patent was applied for at any intellectual property office

- Grant Year - the year in which the patent is granted

- Renewal Year/Annuity Year - the year that the patent was last renewed and the year that it is next due to be renewed

- International Patent Classification (IPC) - the classification representing the type of invention being patented

\section{Business data}

Matching patentee names and addresses to the IDBR results in a patent dataset which, in principle, can be matched to any of ONS's business surveys. For this work, the Business Structure Database was used to provide the basic characteristics of the businesses holding patents.

\section{The Business Structure Database (BSD)}

The Business Structure Database is constructed from an extract of the IDBR ${ }^{2}$, and as such has the same breadth of coverage. An extract from the IDBR is taken annually to create a database of yearly files which can be used for research purposes. Although this database is constructed for research, its origin is an administrative source which was not intended for the same purpose. As such it should be treated with a certain amount of caution.

The administrative sources used to capture business information on the IDBR are primarily VAT registrations (for turnover) and PAYE registrations (for employment). This gives a very wide coverage as any business which is registered for VAT, or has an employee on the PAYE system, is present on the IDBR. However, if only one of these sources is present, the business information which arises from the absent source is imputed. This is particularly the case for new and small businesses. 
As the coverage of the BSD is synonymous with that of the IDBR (at the point in time that the extraction was made) a high match rate can be achieved between the BSD and the patent data which have enterprise references. Such a match allows the following information about patentees to be attached to the patent data:

- Employment/Employees - the number of employees: a) including self-employed and b) excluding self-employed

- Standard Industrial Classification (SIC) - the industry in which the business operates

- Birth Year - the year that the firm first appeared on the IDBR ${ }^{3}$. This is used to calculate firm age

\section{Data matching}

To facilitate the matching of patent data to business data in the Virtual Microdata Laboratory (VML - this is a facility at the ONS which allows secure access to confidential micro-data), the names and addresses of applicants first need to be matched to the IDBR via a string comparison process. This allows the extraction of Enterprise Reference Numbers from the IDBR, and attaches these reference numbers to the patent data in place of the names and addresses. The Enterprise Reference Numbers are used as unique identifiers for businesses in the ONS datasets in the VML. They are therefore used as the linking field for matching the patent and business data via a direct match.

\section{Matching to the IDBR}

The first step of the matching process was to link the patent data names and addresses to enterprises on the IDBR. Some preparatory steps are necessary as there are specific formatting norms which facilitate the matching. Names and addresses need to be subjected to character cleaning before matching. For instance, in the patent data the character ' $\neg$ ' was frequently used in place of a space, and the phrase 'Incorporated in the United Kingdom' preceded a large number of business names. It was also necessary to separate the postcode from the rest of the address and, because the IDBR is a live register of UK businesses, only UK addresses were selected.

Once the initial data cleaning was complete, a list of names and addresses was sent to the Business Register Strategy and Outputs (BRSO) branch at ONS, who provide a service for matching names and addresses to the IDBR. The data sent to the BRSO branch contained only unique names and addresses, along with a unique identifier number. The BRSO branch then returned three separate files; one containing definite matches, one containing multiple matches, and one containing no matches. A definite match is simply when a name and address has been matched to one enterprise on the IDBR. Multiple matches are when a name and address has matched to a number of enterprises on the IDBR. The names and addresses that have found no matches on the IDBR are also returned in a separate file.

A name and address may return multiple matches from the IDBR because businesses can often have a number of separate enterprises on the IDBR. For example pension funds and holdings 
companies may exist alongside the company actually undertaking the business activity. In these cases it is possible to manually identify which enterprise the name and address pertain to. This choice of enterprise can also be checked against the BSD in terms of employment and turnover. Given the number of multiple matches that returned from the IDBR matching process, undertaking this manual matching is not feasible for the whole dataset. However, it was possible to use the unique identifier number to rank the multiple matched names and addresses by the number of patents each holds. Having done so, the manual matching process on those multiple matched names and addresses that hold the most patents was done which increased the definitely matched dataset by a large number of patents for a relatively small number of names and addresses.

Through this process some of the multiple matches were moved into the definite matches file. It was then possible to match these names and addresses back to the original patent data using the unique identifier number. All of the definite matches, multiple matches and no matches were linked back to the patent data in this manner. A marker for each category of match was also added to the data in order to easily calculate the number of patents applicable for each set of matched names and addresses. The matching results in terms of patents are displayed in Table 1.

\section{Table $1 \quad$ Matching patents to enterprises}

\begin{tabular}{lcccc}
\hline & \multicolumn{2}{c}{ Optics } & \multicolumn{2}{c}{ PATSTAT } \\
\hline & Number of patents & Per cent of total & Number of patents & Per cent of total $^{\star}$ \\
Definite Matches & 50,696 & 44 & 51,494 & 56 \\
Multiple Matches & 12,663 & 11 & 16,612 & 18 \\
No matches & 52,209 & 45 & 23,140 & 25 \\
\hline
\end{tabular}

* Numbers may not sum to 100 due to rounding

As sources of patent data are usually from an administrative system, the data has not specifically been constructed for research purposes. One of the challenges often faced by researchers using patent statistics is name harmonisation. The patent statistics databases created from administrative systems often contain many different entries for a single firm. Researchers must therefore harmonise a number of versions of one name into a single version before beginning a name matching process. This need can arise from different spellings, naming conventions, or simply upper and lower case entries ${ }^{4}$. The IDBR matching process overcomes this name harmonization issue automatically. The fuzzy matching process allocates a match score to each case and applies a threshold level to determine if a match is found ${ }^{5}$. For example, the following names and addresses could be sent for matching:

- $\quad$ ADT Ltd

- A D T LTD

- A.D.T PLC

- A. T. Limited
1 Astreet Road, London

1 Astreet Road, London

1 Astreet Road, London

1 Astreet Road, London 
Assuming that there is one enterprise on the IDBR called 'A D T Limited' at this address, these options will all match to the same Enterprise Reference Number and be definite matches. As the Enterprise Reference Number will be the same for all entries, these different versions of the same name have been harmonised by the matching process itself. The other reason for taking this approach is because the IDBR is used as a sampling frame for ONS's business surveys, and the Enterprise Reference Numbers are a common unique identifier across these surveys. This facilitates matching across a number of data sources and greatly increases the breadth of research possibilities.

Another contribution which this matching process makes is in increasing the accuracy with which it is possible to associate a patent with its source. Name matching only exercises may produce a higher match rate, but whilst this is in itself desirable, it is only possible to determine that a business has access to the intellectual property associated with the patent. Using name only matching, it is not possible to determine where the intellectual property was produced. By matching patent applicants by both their name and address is a step closer to being able to make that distinction. There is still likely to be a 'head office' effect in a number of cases. An invention may occur at a particular address, and then the patent may be applied for from the business' head office. In these cases, the patent would be matched to the head office, possibly introducing a bias to any spatial analyses which these matched data could be used for.

Whilst there are advantages to matching patent applicants to the IDBR, there are also limitations to this approach. The IDBR is a live register of businesses in the UK, and is updated daily. When a name and address matching exercise is done, it is the IDBR at that point in time which is being used. If a local unit has changed name, but is undertaking the same activity in the same location, then this local unit will be updated on the IDBR to reflect the name change. Subsequently matching a patent application made under the old name is therefore likely to produce a no match result.

\section{Matching patent and business data}

The patent datasets which were uploaded to the VML had the names and addresses of applicants removed for data security purposes. However, upon completion of the name and address matching to the IDBR these patent datasets had Enterprise Reference Numbers in place of these names and addresses when a definite match was found. This leaves an Optics dataset which includes all patents applied for from a UK address to the UK IPO; and a PATSTAT dataset which includes all of the patents applied for from a UK address to the EPO.

For the purposes of this work, these datasets are appended together then matched to the BSD using the Enterprise Reference Number when it is available. Yearly BSD files are used in combination with the application year information from the patent data ${ }^{6}$. The resulting matched dataset includes all of the patent information from Optics and PATSTAT along with business information from the BSD for the applicant, when the applicant found a definite match on the IDBR. The use of yearly BSD files for matching ensures that the business information is relevant at the year of application. The cross sectional results presented in this article were produced using this dataset. Yearly matched datasets were also created to form a time series so that trends in the stock of live patents could be investigated. 


\section{Results}

\section{Distributions of patents and patentees by patentee age}

The distribution of patents by patentee age presented in Figure 1a can be interpreted as representing the number of patents for which the patentee business is in a particular age band. For Figure $\mathbf{1 b}$, the number of patents was not taken in to account. This figure simply represents the age distribution of firms in patent data at the year of application (Optics and PATSTAT) ${ }^{7}$. Both of these distributions display a pronounced spike at the top coded end of the distribution. More than 50 per cent of patents are owned by businesses greater than 20 years old. Correspondingly, more than 45 per cent of patentees are greater than 20 years old. A feature of the BSD, which was used to calculate the patentee age, is that there are a large number of enterprises which have a birth year of 1973. This arises from the history of the IDBR. These enterprises do not have an accurately known birth year, and this has been allocated as 1973. This means that analysis of age can lose some meaningfulness at the upper end of the age distribution, and these results should be treated with caution.

\section{Figure 1a Distribution of patents by patentee age}

Per cent of patents

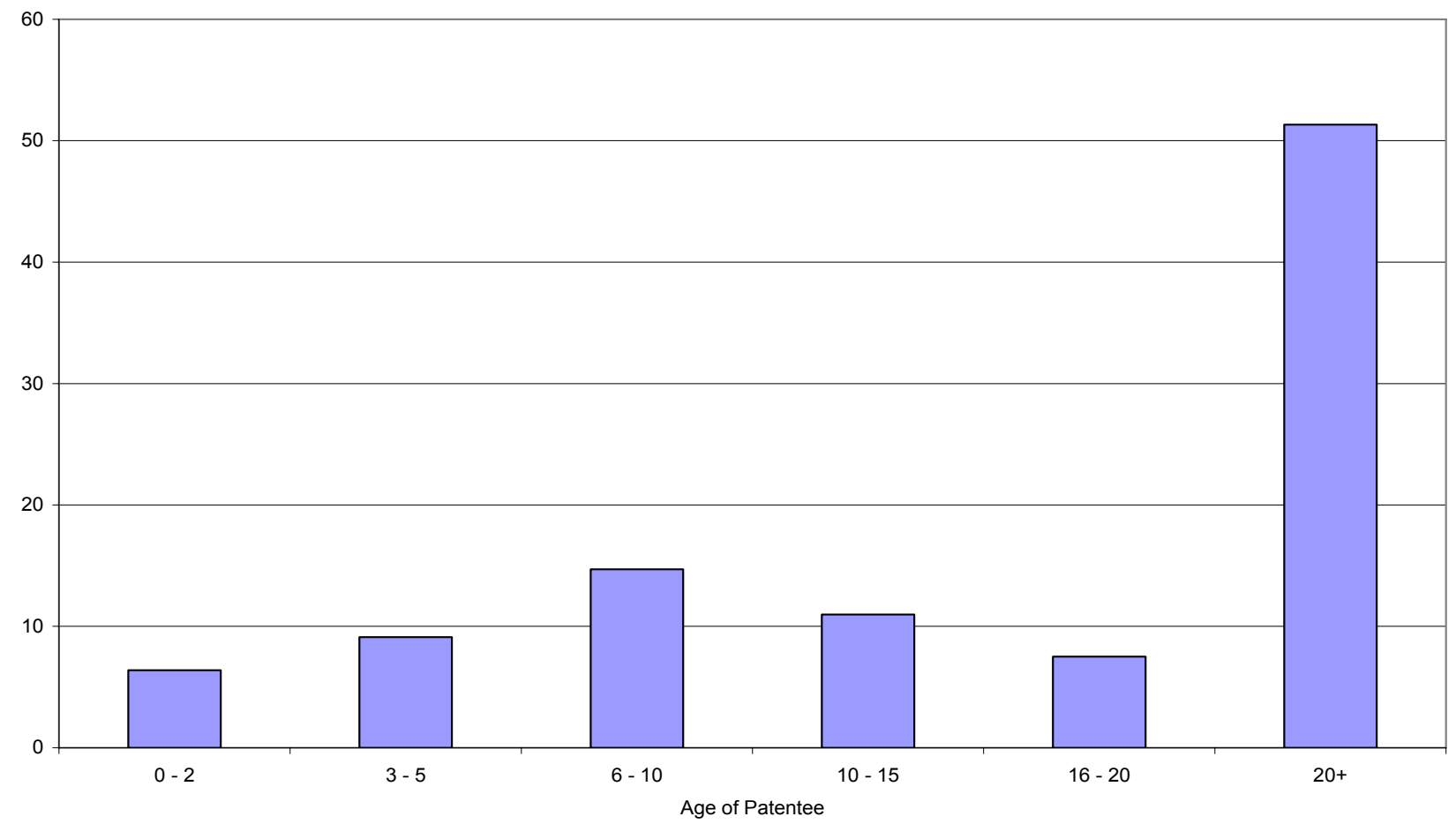

Source: Intellectual Property Office and Office for National Statistics 


\section{Figure 1b Distribution of patentees by age}

Per cent of patentees

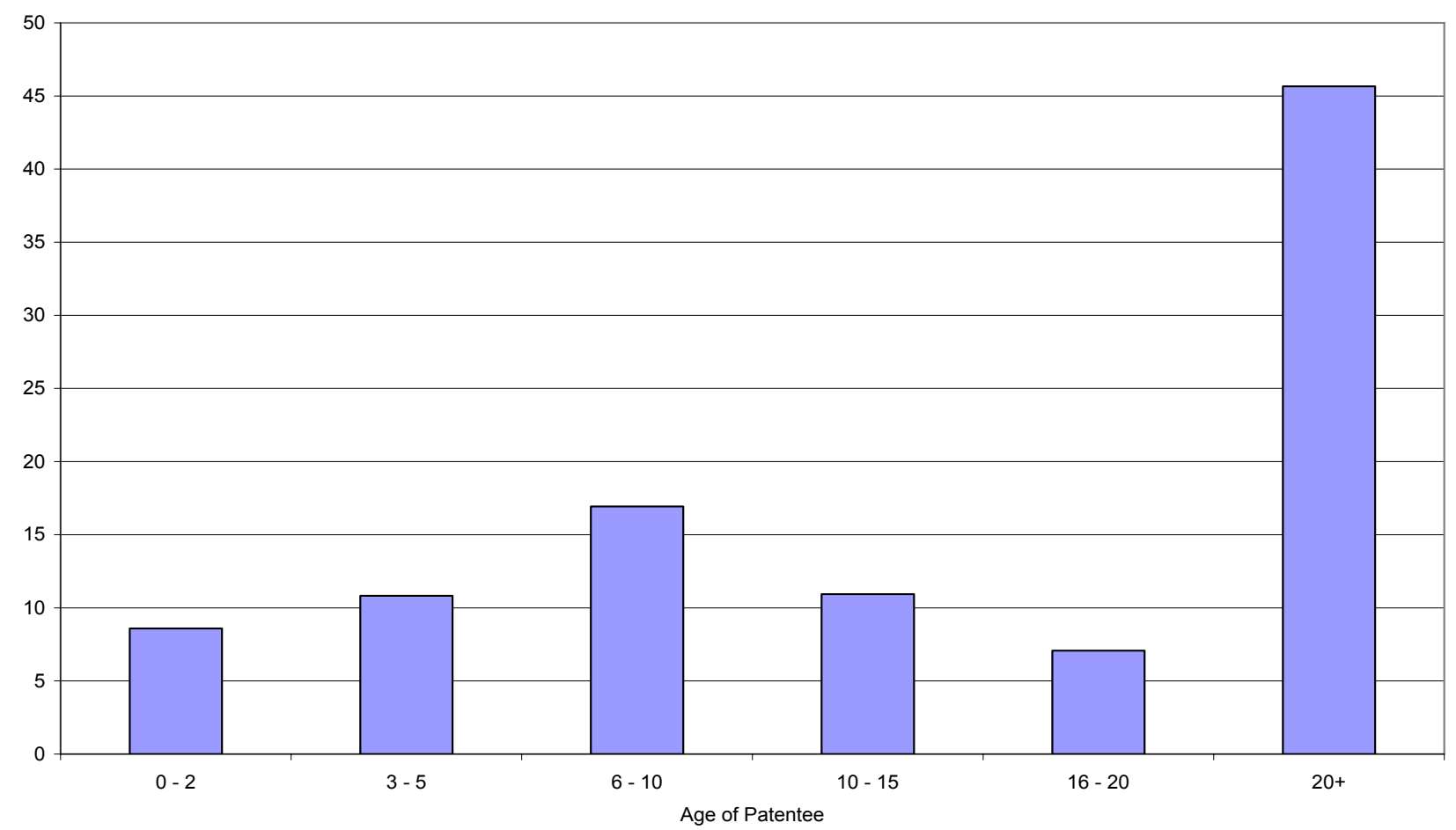

Source: Intellectual Property Office and Office for National Statistics

When considering these distributions excluding the top category, both display a similar pattern. Each of the distributions now has a shape which is at least superficially similar to that of a normal distribution. The 6-10 year age band of patentees hold the most patents and also represent the largest group of patentees. The distributions then reduce towards each tail. Note that the figures presented here were produced using the whole dataset. This procedure was repeated for a number of different time periods within the data and the results did not change materially from those presented.

\section{Distributions of patents and patentees by patentee size}

The size distributions presented in Figures $\mathbf{2 a}$ and $\mathbf{2} \mathbf{b}$ show a contrast between the distribution of patents by their owner's size and the distribution of the patentees themselves. The number of patents held by firms of different sizes is relatively even, with the majority of size bands having 5 per cent to 10 per cent of patents. Even the size band with the largest share, the 10,000 employees or more size band, holds only 17 per cent of patents. When considering only the number of firms which patent, the distribution is markedly different. The dominant category in this case is firms with 1 to 9 employees, making up over 30 per cent of patentees. This can be used as an indication of the average number of patents held by firms in different size bands. Firms with 1 to 9 employees dominate the patentees, but on average they hold fewer patents. Conversely, firms with 1,000 to 4,999 employees make up just 2 per cent of patentees but own more than 15 per cent of patents ${ }^{8}$. 


\section{Figure 2a Distribution of patents by patentee size}

Per cent of patents

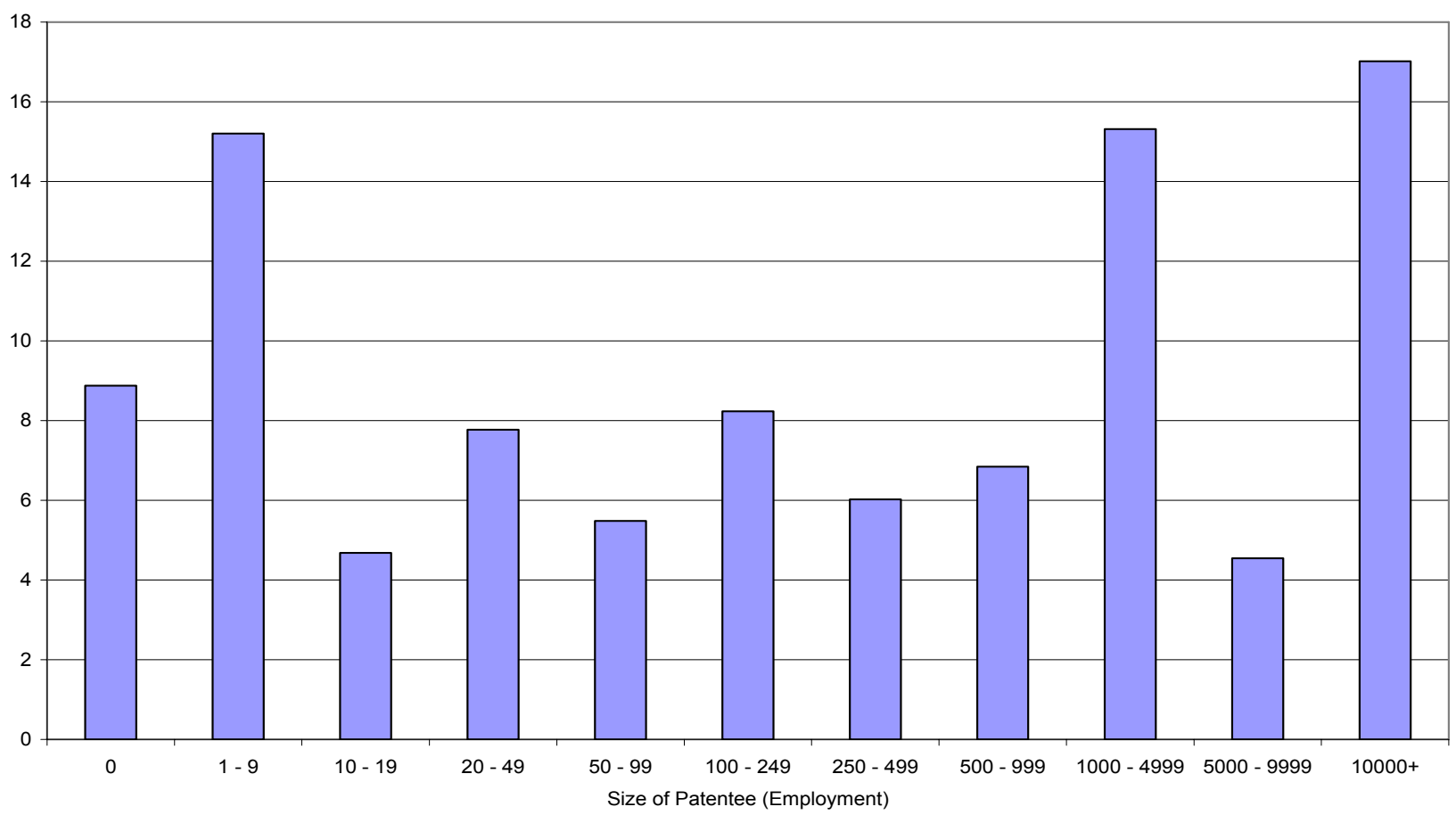

Source: Intellectual Property Office and Office for National Statistics

\section{Figure 2b Distribution of patentee size}

Per cent of patentees

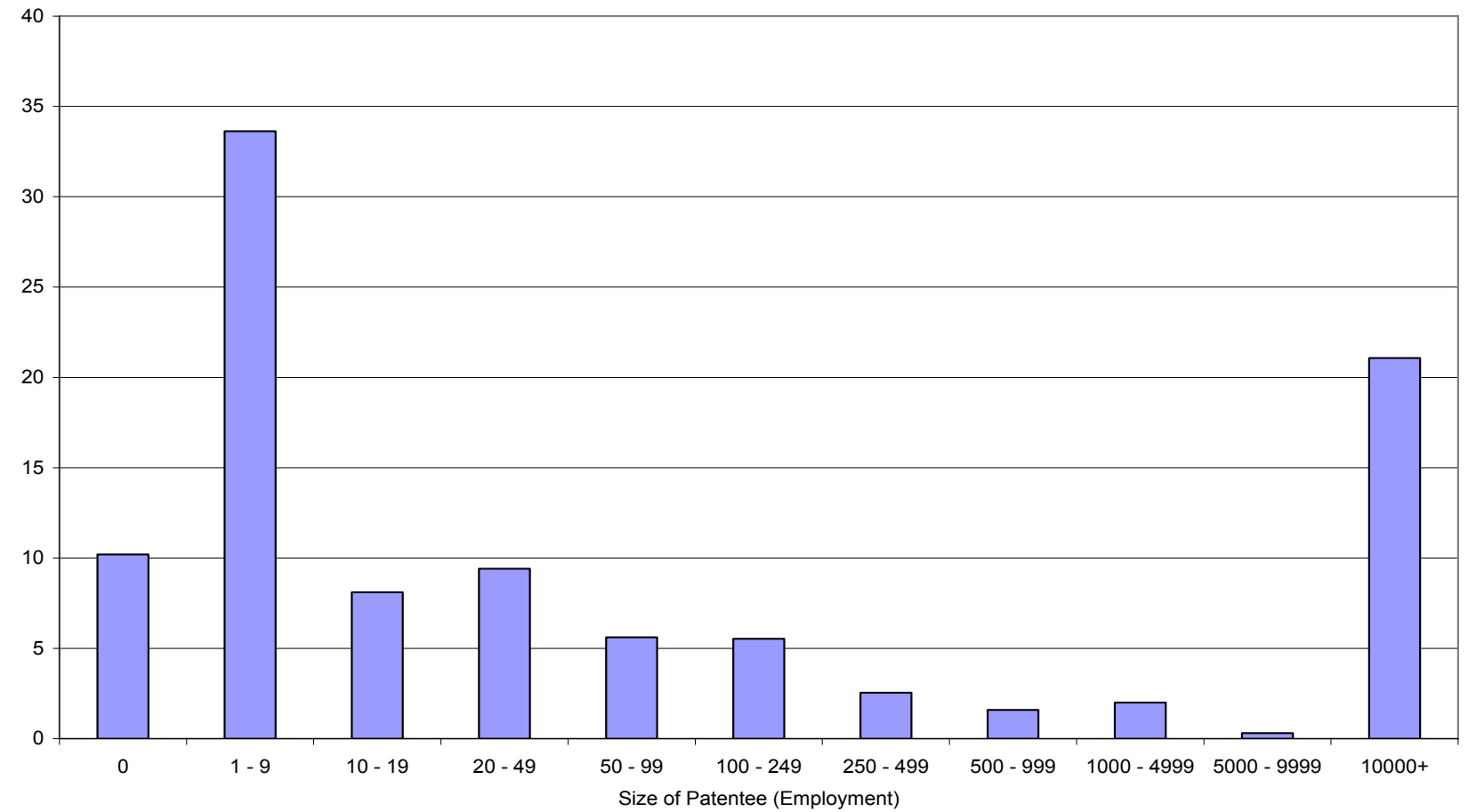

Source: Intellectual Property Office and Office for National Statistics 


\section{Stock of patents}

To define a patent as live, the renewal information from the patent data is used in conjunction with the yearly BSD files. For a given year in the dataset, each patent can be in one of four states: applied for and granted; applied for and not yet granted; applied for, granted and subsequently lapsed; and not yet applied for. This last category occurs because we are considering the whole patent dataset, and patents applied for in more recent years are obviously not live in the years before application. For example, a patent in our dataset which was applied for in 2003 will not be considered a live patent in 1997. Patents which have lapsed by a certain year are no longer live in that year. Both of the first two categories are taken as live patents in this analysis. The first being obvious, these are the patents which have been granted and are enforceable. However, the patents which have been applied for and published but not granted still have some force of protection. This arises from the fact that a patent pending is likely to discourage competitors from copying the invention. If a competitor was to do so, they run the risk of the patent being granted and finding themselves liable to pay the inventor any gains from the copied invention.

Figure 3a indicates that the stock of patents which are live in a given year is steadily increasing over time. There is a turning point at the end of the time period, but this is likely to represent the lower number of published patents we have data for in 2008 and 2009. It seems unlikely to represent a genuine reduction in the stock of patents. Similarly, the number of businesses holding live patents is increasing over the time (Figure $\mathbf{3 b}$ ).

\section{Figure $3 a \quad$ Stock of live patents}

Live patents

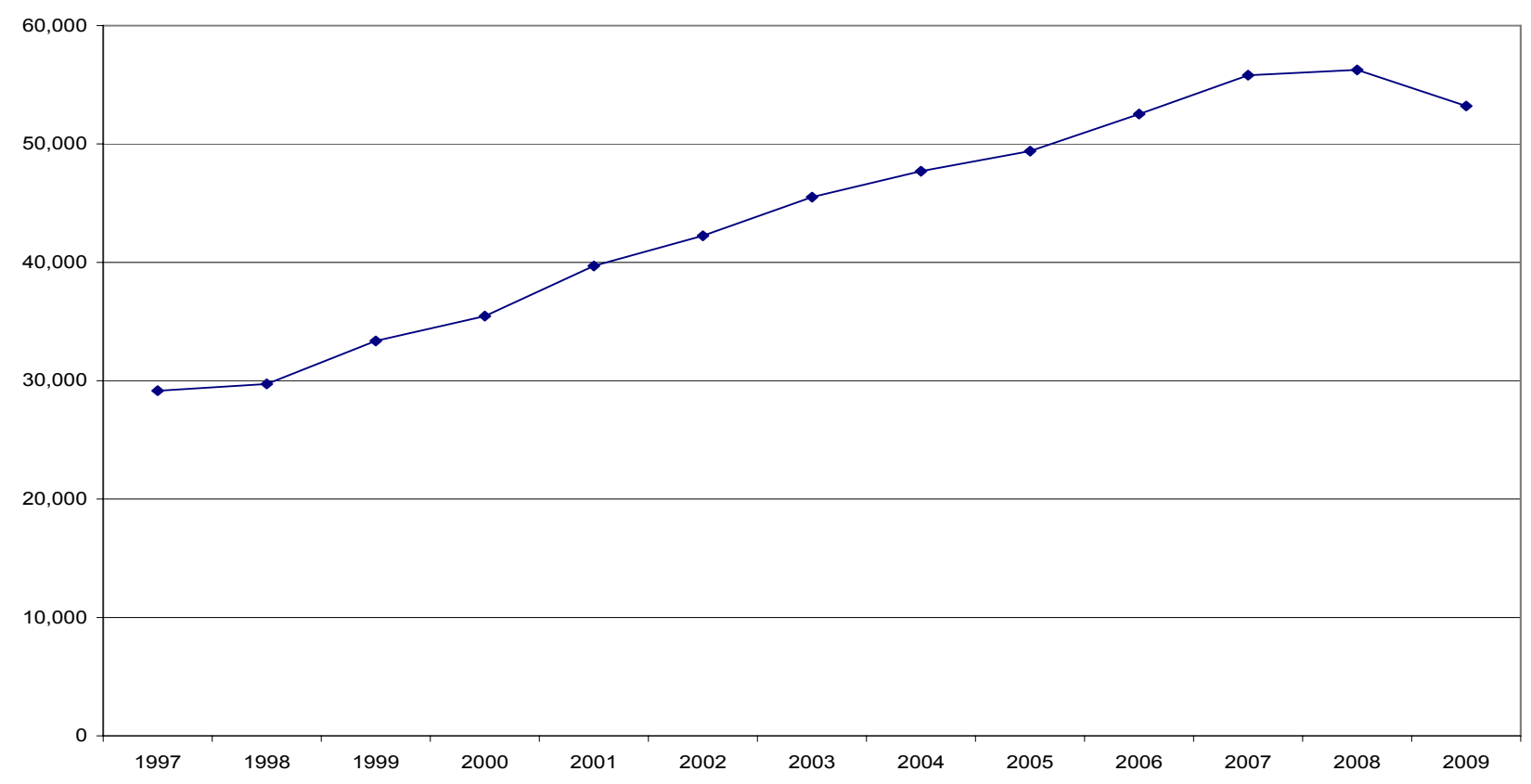

Source: Intellectual Property Office and Office for National Statistics 


\section{Figure $3 b \quad$ Patentees holding live patents}

Number of patentees

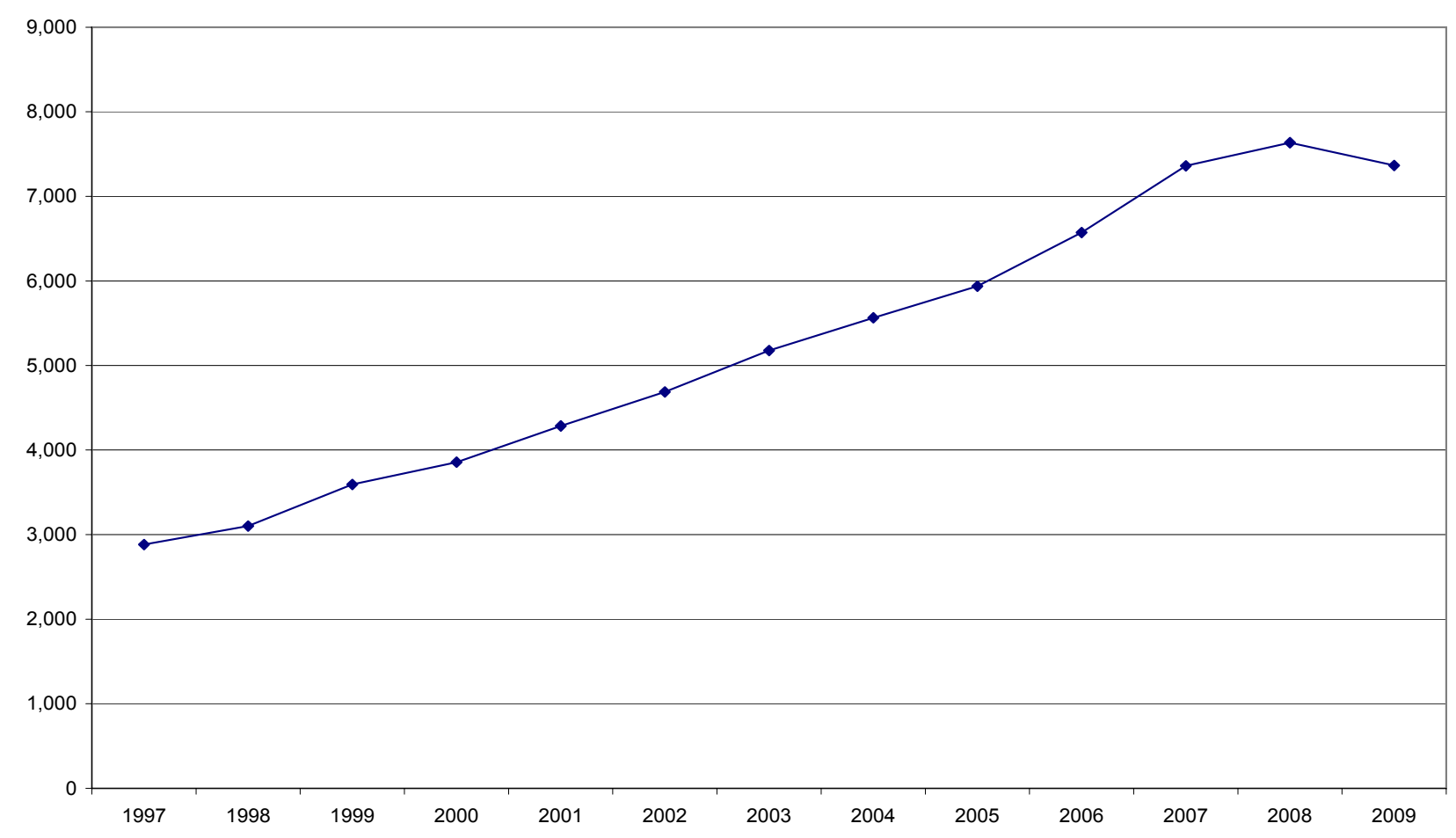

Source: Intellectual Property Office and Office for National Statistics

\section{Businesses, non-businesses and IPC codes}

The matching process distinguishes businesses from individuals to some extent. Any name and address that found either a definite match or multiple matches on the IDBR must be a business. For the analysis in this article, we also identify a number of businesses from the no match file. This is achieved by searching for certain strings within a name variable on the data. For example, any name with 'LTD', 'Ltd', 'Plc' and so on in it was defined as a business. At this point, there are some remaining businesses in the no match file which have not been possible to identify. For the purposes of this analysis, these are considered individuals. When interpreting the results in Table 2 , it should be noted that there are no individuals defined as businesses but it is likely that there are a small number of businesses defined as non-businesses.

Overall, Table 2 shows the number of patents owned by businesses to be 2.6 times the number of patents owned by individuals. A breakdown of these results by the type of invention (IPC code) tells broadly the same story, with some specific variations represented by the highlighted rows. 'Sports, games and amusements' is the only IPC category in which the number of patents held by individuals is higher than the number of patents held by business. Patents in all other categories of invention are held mostly by businesses. In a couple of categories, this result is particularly pronounced (IPC C07 - Organic chemistry and IPC C11 - Oils, fats, detergents and so on). Whilst it may be intuitive for this to occur in the chemical classifications, these results also relate to relatively few observations. 


\section{Table $2 \quad$ Patents held by businesses and non-businesses}

\begin{tabular}{|c|c|c|c|}
\hline IPC Code (3 character) & Business & $\begin{array}{l}\text { Non- } \\
\text { Business }\end{array}$ & $\begin{array}{l}\text { Business/ } \\
\text { Non-Business }\end{array}$ \\
\hline $\begin{array}{l}\text { A01 - Agriculture; Forestry; Animal Husbandry; } \\
\text { Hunting; Trapping; Fishing }\end{array}$ & 2,788 & 2,268 & 1.2 \\
\hline A23 - Foods or Foodstuffs; Their Treatment & 1,524 & 267 & 5.7 \\
\hline $\begin{array}{l}\text { A47 - Furniture; Domestic Articles or Appliances; } \\
\text { Coffee Mills; Spice Mills; Suction Cleaners }\end{array}$ & 3,353 & 3.263 & 1.0 \\
\hline A61 - Medical or Veterinary Science; Hygiene & 11,542 & 3,670 & 3.1 \\
\hline A63 - Sports; Games; Amusements & 1,370 & 2,536 & 0.5 \\
\hline B01 - Physical or Chemical Processes or Apparatus & 2,485 & 520 & 4.8 \\
\hline B60 - Vehicles in General & 3,941 & 2,368 & 1.7 \\
\hline B62 - Land Vehicles other than on Rails & 1,165 & 1,119 & 1.0 \\
\hline $\begin{array}{l}\text { B65 - Conveying; Packing; Storing; Handling Thin or } \\
\text { Filamentary Material }\end{array}$ & 5,720 & 2,399 & 2.4 \\
\hline C07 - Organic Chemistry & 5,607 & 321 & 17.5 \\
\hline C08 - Organic Macromolecular Compounds & 1,794 & 239 & 7.5 \\
\hline $\begin{array}{l}\text { C11 - Animal or Vegetable Oils, Fats, } \\
\text { Fatty Substances or Waxes; Fatty Acids Therefrom; Detergents; Candles }\end{array}$ & 1,563 & 49 & 31.9 \\
\hline $\begin{array}{l}\text { C12 - Biochemistry; Beer; Spirits; Wine; Vinegar; Microbiology; } \\
\text { Enzymology; Mutation or Genetic Engineering }\end{array}$ & 2,769 & 382 & 7.2 \\
\hline E04 - Building & 3,204 & 2,269 & 1.4 \\
\hline E05 - Locks; Keys; Windowor Door Fittings: Safes & 1.955 & 796 & 2.5 \\
\hline $\begin{array}{l}\text { E06 - Doors; Windows; Shutters; Or Roller Blinds in } \\
\text { General; Ladders }\end{array}$ & 1,357 & 1,008 & 1.3 \\
\hline F16 - Engineering Elements or Units & 6,732 & 2,056 & 3.3 \\
\hline G01 - Measuring; Testing & 10,595 & 2,676 & 4.0 \\
\hline G02 - Optics & 2,314 & 687 & 3.4 \\
\hline G06 - Computing; Calculating; Counting & 6,332 & 1,308 & 4.8 \\
\hline G08 - Signalling & 997 & 811 & 1.2 \\
\hline $\begin{array}{l}\text { G09 - Educating; Cryptography; Display; Advertising; } \\
\text { Seals }\end{array}$ & 1,393 & 1,117 & 1.2 \\
\hline H01 - Basic Electric Elements & 6,213 & 1,415 & 4.4 \\
\hline H02 - Generation, Conversion, or Distribution of Electric Power & 1,894 & 645 & 2.9 \\
\hline H03 - Basic Electronic Circuitry & 1,730 & 234 & 7.4 \\
\hline H04 - Electric Communication Technique & 9,905 & 1,720 & 5.8 \\
\hline H05 - Electric Techniques not Otherwise Provided for & 1,248 & 304 & 4.1 \\
\hline Other & 37,674 & 16,352 & 2.3 \\
\hline Total & 139,164 & 52,799 & 2.6 \\
\hline
\end{tabular}

Grey rows represent businesses holding more than three times the patents of individuals. Blue rows represent individuals holding more patents than business.

Source: Intellectual Property Office and Office for National Statistics 


\section{Industry and IPC code}

The list of industries shown in this article is obviously not extensive. A few industries which appear to be particularly relevant for patent statistics have been analysed to provide an indication of the link that may exist between industry and the type of innovation being patented ${ }^{9}$. Standard Industrial Classification (SIC) codes have been grouped to provide a subset of industries, and a breakdown of patents by IPC code (at the 3 character level) is presented for each industry. A subset of IPC codes is also selected for each industry. However this selection is empirically driven, the classifications chosen for each industry were simply those with any significant proportion of patents (3 per cent or more).

IPC codes which account for less significant amounts of patents are grouped together in a catchall category named 'Other'. Broadly the results of this analysis, shown in Table 3, seem intuitive. Businesses in the chemical and pharmaceutical industry predominantly hold patents classified in chemicals and medical science; businesses in the motor vehicle industry tend to hold patents in vehicles, engines and engineering; and businesses in the computer industry mostly hold patents in computing.

The breakdown for the manufacture of electrical and optical equipment industry is much more evenly distributed. Though measuring and electrical elements are the inventions which are patented most, there are a larger number of other types of inventions being patented by businesses in this industry.

The research and development industry patents inventions predominantly in a few key areas. Medical science; biochemistry and microbiology; organic chemistry; and measuring and testing make up nearly half of the patents by this industry. The remaining patents held by research and development businesses are spread across the many remaining IPC codes.

The industry classified as other business activities comes from the services section of the SIC codes. This subset of SIC codes contains business management services; holdings companies; legal services; and a number of other business administration related activities. One phenomenon that was observed when completing the matching process and manually checking some of these matches, was enterprises changing from a manufacturing SIC code to other business activities. This may represent growth in the business, whereby the original entity becomes a holdings company which is associated with a number of subsidiary enterprises. It is difficult to tell the significance of this phenomenon - partly because this information only exists from 1997 onwards so any business which had made this change prior to 1997 would appear as a holdings company for the whole time period. The types of patents held by these companies is somewhat varied, with medical science being the largest category. 


\section{Table 3 Innovations being patented by select industries}

Manufacture of chemicals and pharmaceuticals (SIC 24000-24999)

\begin{tabular}{lccc}
\hline IPC & Patents & Per cent & Businesses \\
\hline A61 - Medical or Veterinary Science; Hygiene & 312 & 14.6 & 46 \\
B01 - Physical or Chemical Processes or Apparatus & 142 & 6.7 & 19 \\
C07 - Organic Chemistry & 510 & 23.9 & 29 \\
C08 - Organic Macromolecular Compounds & 226 & 10.6 & 27 \\
Other & 942 & 44.2 & 323 \\
Total & $\mathbf{2 , 1 3 2}$ & & \\
\hline
\end{tabular}

Manufacture of electrical and optical equipment (SIC 30000-33999)

\begin{tabular}{lccc}
\hline IPC & Patents & Per cent & Businesses \\
\hline A61 - Medical or Veterinary Science; Hygiene & 301 & 5.2 & 78 \\
B60 - Vehicles in General & 200 & 3.5 & 20 \\
F16 - Engineering Elements or Units & 170 & 2.9 & 54 \\
G01 - Measuring; Testing & 902 & 15.6 & 194 \\
G02 - Optics & 198 & 3.4 & 41 \\
G06 - Computing; Calculating; Counting & 317 & 5.5 & 59 \\
H01 - Basic Electric Elements & 873 & 15.1 & 151 \\
H02 - Generation, Conversion, or Distribution of Electric Power & 188 & 3.3 & 69 \\
H03 - Basic Electronic Circuitry & 350 & 6.1 & 40 \\
H04 - Electric Communication Technique & 966 & 16.7 & 91 \\
Other & 1,315 & 22.8 & 573 \\
Total & 5,780 & & \\
\hline
\end{tabular}

Manufacture of motor vehicles; other transport equipment (SIC 34000-34999)

\begin{tabular}{lccc}
\hline IPC & Patents & Per cent & Businesses \\
\hline B60 - Vehicles in General & 718 & 17.1 & 67 \\
B62 - Land Vehicles other than on Rails & 131 & 3.1 & 27 \\
E05 - Locks; Keys; Windowor Door Fittings: Safes & 117 & 2.8 & 13 \\
F01 - Machines or Engines in General & 291 & 6.9 & 11 \\
F02 - Combustion Engines & 422 & 10.1 & 18 \\
F16 - Engineering Elements or Units & 692 & 16.5 & 44 \\
G01 - Measuring; Testing & 363 & 8.6 & 23 \\
H01 - Basic Electric Elements & 151 & 3.6 & 17 \\
Other & 1,314 & 31.3 & 310 \\
Total & 4,199 & & \\
\hline
\end{tabular}


Computer and related activities (SIC 72000-72999)

\begin{tabular}{lccc}
\hline IPC & Patents & Per cent & Businesses \\
\hline G01 - Measuring; Testing & 25 & 11.4 & 18 \\
G06 - Computing; Calculating; Counting & 67 & 30.6 & 30 \\
H04 - Electric Communication Technique & 27 & 12.3 & 20 \\
Other & 100 & 45.7 & 84 \\
Total & $\mathbf{2 1 9}$ & & \\
\hline
\end{tabular}

Research and development (SIC 73000-73999)

\begin{tabular}{lccc}
\hline IPC & Patents & Per cent & Businesses \\
\hline A61 - Medical or Veterinary Science; Hygiene & 214 & 15.1 & 39 \\
C07 - Organic Chemistry & 169 & 11.9 & 20 \\
C12 - Biochemistry; Beer; Spirits; Wine; Vinegar; Microbiology; Enzymology; & & & 32 \\
Mutation or Genetic Engineering & 158 & 11.1 & 41 \\
G01 - Measuring; Testing & 135 & 9.5 & 267 \\
Other & 744 & 52.4 & 1,420 \\
Total & & & \\
\hline
\end{tabular}

Other business activities (SIC 74000-74999)

\begin{tabular}{lccc}
\hline IPC & Patents & Per cent & Businesses \\
\hline A23 - Foods or Foodstuffs; Their Treatment & 398 & 5.7 & 22 \\
A61 - Medical or Veterinary Science; Hygiene & 1,082 & 15.6 & 58 \\
B65 - Conveying; Packing; Storing; Handling Thin or Filamentary Material & 378 & 5.4 & 92 \\
C07 - Organic Chemistry & 635 & 9.1 & 19 \\
F16 - Engineering Elements or Units & 256 & 3.7 & 109 \\
G01 - Measuring; Testing & 471 & 6.8 & 130 \\
Other & 3,721 & 53.6 & 1,366 \\
Total & 6,941 & & \\
\hline
\end{tabular}

Source: Intellectual Property Office and Office for National Statistics

\section{Concluding remarks}

This article provides a description of patent data matching, along with some initial results from the matched dataset. The data sources used in this paper are very rich and will be used for a wide range of further research. Having access to the information contained in Optics has provided a unique opportunity to begin research on previously unavailable data. Along with this, using the 
IDBR for matching names and addresses has given rise to the potential for exploiting these data alongside large amounts of business information which is present in ONS surveys.

Trends which have become apparent from the initial descriptive results seem predominantly intuitive. The findings suggest that there are many small businesses that own patents, but each of these owns fewer than larger businesses. Businesses hold more patents than individuals in total, and this holds in the vast majority of cases when different types of patents are taken into account. There does seem to be a link between the industry the business is classified in and the type of inventions the business patents. Whilst businesses may not patent one type of invention exclusively, the industries as a whole appear to be patenting the types of inventions that would be expected.

Whilst it should be accepted that any data matching exercise has its limitations, these results can be considered along with other quality checks. Taken as a whole, the results provide a quality assurance of the data matching process. It appears that the final matched datasets are producing intuitive results, and that these datasets are an effective research tool.

\section{Notes}

1. See for example Thoma et al. (2010), Motohashi (2009), Helmers and Rogers (2008)

2. www.statistics.gov.uk/idbr/idbr.asp

3. Note: this is not necessarily when the business started trading, a business may have existed prior to registering for VAT or employing a worker on PAYE.

4. See Thoma et al (2010) for a detailed discussion.

5. Please contact maus@ons.gsi.gov.uk for a document explaining this process.

6. All applications prior to 1997 have been matched to BSD 1997, as this is the earliest year in the BSD.

7. This approach is follows OECD 2010. This is also the case for the size distributions presented later.

8. The figures presented were produced using the whole dataset. This procedure was repeated for a number of different time periods within the data and the results do not change materially from those presented.

9. The IPO Facts and Figures $2008 / 2009$ document was used as an indication of which industries are most relevant. 


\section{Disclaimer}

This work contains statistical data from ONS which is Crown copyright and reproduced with the permission of the controller of HMSO and Queen's Printer for Scotland. The use of the ONS statistical data in this work does not imply the endorsement of the ONS in relation to the interpretation or analysis of the statistical data. This work uses research datasets which may not exactly reproduce National Statistics aggregates.

\section{Acknowledgements}

The author is grateful to the UK Intellectual Property Office for providing the funding for this work. Thanks go to Khalid Khan, Eric Scheffel and Felix Ritchie from the Office for National Statistics for helpful support and advice and also to Peter Evans, Benjamin Mitra-Kahn, and Tony Clayton from the Intellectual Property Office for comments on an earlier version of the article. For support with the data matching process, the author appreciates advice from Verity Sweeney and Mike Villars of the Business Register Strategy and Outputs branch at ONS.

\section{Contact}

elmr@ons.gov.uk

\section{References}

Balasubramanian N and Sivadasan J (2009) 'What Happens when Firms Patent? New Evidence from US Economic Census Data' Working Papers 08-03, Centre for Economic Studies, U.S. Census Bureau

Evans P and Khan M K N (2009) 'The Characteristics of Patenters' Economic \& Labour Market Review, Vol 3, No 12, pp 20-27

Griliches Z (1990) 'Patent Statistics as Economic Indicators: A Survey', Journal of Economic Literature, Vol XXVIII, pp 1661-1707

Hall B H, Thoma G and Torrisi S (2007) 'The Market Value of Patents and R\&D: Evidence from European Firms' NBER Working Paper Series, No 13426

Helmers C and Rogers M (2008) 'Innovation and the Survival of New Firms Across British Regions' Economics Series Working Papers, University of Oxford, Department of Economics, No 416.

Intellectual Property Office (2010) 'Facts and Figures 2008-2009' http://www.ipo.gov.uk/aboutfacts0809.pdf

Kerr W and Fu S (2006) 'The Industry R\&D Survey: Patent Database Link Project', Working Papers 06-28, Centre for Economic Studies, U.S. Census Bureau 
Magerman T, Van Looy B, Song X (2006) 'Data Production Methods for Harmonized Patent Statistics: Patentee Name Harmonization', K .U .Leuven FETEW MSI Research Report 0605, Leuven

Motohashi K (2009) 'Software Patent and its Impact on Software Innovation in Japan', Discussion papers 09038, Research Institute of Economy, Trade and Industry (RIETI)

OECD (2008) 'Compendium of Patent Statistics 2008'

OECD (2009) 'An Agenda for Policy Action on Innovation' 2009 Interim Report on the OECD Innovation Strategy

OECD (2010) 'Matching Patent and Business Data to Investigate Firms' Innovativeness' Working Party on Industrial Analysis

Ozman M (2007) 'Breadth and Depth of Main Technology Fields: An empirical investigation using patent data,' STPS Working Papers 0701, STPS - Science and Technology Policy Studies Center, Middle East Technical University

Thoma G, Torrisi S, Gambardella A, Gullec D, Hall B H and Harhoff D (2010) 'Harmonizing and Combining Large Datasets - An Application to Firm-Level Patent and Accounting Data', NBER Working Paper Series, No 15851 